\title{
Leukemia-Associated Non-Coding IGF1R Activator RNA 1
}

National Cancer Institute

\section{Source}

National Cancer Institute. Leukemia-Associated Non-Coding IGF1R Activator RNA 1. NCI

Thesaurus. Code C118120.

Leukemia-associated non-coding IGF1R activator RNA 1 is encoded by the human LUNAR1 gene. This non-coding RNA plays a role in both leukemogenesis and Notch signaling. 